\title{
EMPREENDEDORISMO E O PROCESSO DE CRIAÇÃO DE UMA NOVA ORGANIZAÇÃO
}

\author{
Felipe Leal Alves Ferreira - UFPR/Pontifícia Universidade Católica do Paraná ${ }^{1}$ \\ Fernando Antônio Prado Gimenez - Universidade Federal do Paraná \\ Paulo Otávio Mussi Augusto - Pontifícia Universidade Católica do Paraná
}

\begin{abstract}
Resumo: Katz e Gartner (1988) apontaram a necessidade dos estudos em empreendedorismo se focar nos momentos iniciais da formação de um novo empreendimento, explorando o que denominaram propriedades das organizações emergentes. Dessa forma, este artigo relata os resultados de uma pesquisa cujo objetivo foi verificar como se dá a criação de uma nova organização, enfocando as dimensões propostas por Katz e Gartner (1988). Para isso, foram realizadas entrevistas com quatro empreendedores da cidade de Curitiba-PR. A análise das respostas foi realizada pela técnica de análise da narrativa e os resultados apontaram, em geral, as seguintes considerações: a) os empreendedores procuram embasamento técnico preliminar para criar sua organização, seja por parcerias ou por aprimoramento pessoal; b) o estudo do mercado, concorrentes e clientes são atividades prioritárias executadas por meio de pesquisas, contatos e reprodução de algumas práticas já institucionalizadas no contexto em que atuam; c) atividades-meio como Marketing e Finanças são prioridade e se resumem em atividades básicas para gestão da empresa; d) o plano de negócios é formalizado, mas não é revisto e atualizado; e) internet e redes sociais são considerados de fundamental importância na divulgação da empresa no mercado; f) os recursos utilizados, em sua maioria, são do próprio empreendedor; g) parcerias e o desenvolvimento do produto e serviço - quando não são reformulados quase que por completo - são atividades constantes, o que denota um aprendizado e aprimoramento contínuos. Sugere-se que, em pesquisas futuras, outros processos de criação de novas organizações sejam acompanhados por um tempo ainda maior para análise das ações dos empreendedores em seus processos de empreender e gerir seus negócios.
\end{abstract}

Palavras-chave: Empreendedorismo; Criação de Nova Organização; Propriedades das Organizações Emergentes; Empreendedor.

\section{ENTREPRENEURSHIP AND THE CREATING PROCESS OF A NEW ORGANIZATION}

Abstract: Katz and Gartner (1988) proposed that entrepreneurship research should focus upon the initial stages of formation of a new enterprise, suggesting that the properties of emerging organizations should be explored. Thus, this paper relates results of a research that aimed to reveal how is the creation of a new organization, based on four dimensions proposed by Katz and Gartner (1988). For this purpose, interviews were conducted with four entrepreneurs in Curitiba-PR. The analysis of the answers was performed by technique of

\footnotetext{
${ }^{1}$ E.mail: felipe.leal@ufpr.br - Endereço: Av. Prof. Lothario Meissner, $6322^{\circ}$ andar - Jardim Botânico, Curitiba - PR, CEP 80210-170.

${ }^{2}$ E.mail: fapgimenez2009@hotmail.com

${ }^{3}$ E.mail: paulo.augusto@pucpr.br
}

DOI: 10.14211regepe32128. FERREIRA, F. L. A.; GIMENEZ, F. A. P.; AUGUSTO, P. O. M. Empreendedorismo e o processo de criação de uma nova organização. Revista de Empreendedorismo e Gestão de Pequenas Empresas, v.3, n.2, p. 70-93, 2014. 
Narrative Analysis. The results indicated that: a) the entrepreneurs search for technical support before create an organization, either through personal development or partnerships; b) the study of the market, competitors and clients are activities considered to be priority, being executed through research, contacts and reproduction of institutionalized practices in their business context; c) Marketing and Finance are the main concern of entrepreneurs and are the basic activities in the new venture management; d) the business plan is formalized, however is not revised or actualized; e) internet and social networks are considered to be of fundamental relevance for the disclosure in the market; f) resources come mostly from own entrepreneurs savings; g) partnerships and product development are constant activities in the entrepreneurs routine implying continuous learning and improvement. Future longitudinal studies are recommended in order to better describe entrepreneurs' action in their entrepreneurial and managerial processes.

Keywords: Entrepreneurship; Creation of a New Organization; Properties of Emerging Organizations; Entrepreneur.

\section{Introdução}

De acordo com a pesquisa internacional Global Entrepreneurship Monitor (GEM) que estuda o nível de empreendedorismo em vários países, em 2013, no Brasil, a taxa de empreendedorismo em estágio inicial foi de 17,3\%. Como estágio inicial, a GEM abrangeu um número de pessoas de 18 a 64 anos de idade envolvidas em negócios com no máximo quarenta e dois meses (ou três anos e meio) de atividade. Este patamar representa que 21,3 milhões de brasileiros estavam envolvidos em negócio próprio, que estava sendo criado ou iniciado.

$\mathrm{Na}$ literatura consultada, o empreendedorismo também mostra seu crescimento em importância. Nesse sentido, Filion (1999) destaca que na década de 1980 esta área acabou adentrando em grande parte nas ciências em geral. Também previu a probabilidade de que no futuro o campo do empreendedorismo se tornasse o que ele chamou de "um dos principais pontos de aglutinamento das ciências humanas", sendo que a área tem atraído estudiosos de diversos campos do conhecimento (FILION, 1999, p. 12).

Com toda essa especulação, algumas indagações surgem diante do tema do empreendedorismo. Sexton (1988 apud GOMES; LIMA; CAPELLE, 2012) realizou um estudo intitulado "O campo do empreendedorismo: está crescendo ou apenas se tornando maior?". Nesse estudo, o autor afirma que apesar da resposta possuir diferentes formas de análise, o campo está se tornando maior e também crescendo. No entanto, esse crescimento depende de interligar as conquistas do passado com 
as novidades do presente para se chegar aos desejos e aspirações futuras para o empreendedorismo (SEXTON, 1988 apud GOMES; LIMA; CAPELLE, 2012).

Outra importante indagação é a de Sarasvathy (2004) que se voltou em torno de perguntas e questões que preocupam o empreendedorismo, defendendo a reformulação de alguns problemas de pesquisa desta área. Nesse sentido, perguntas que são feitas podem impedir o surgimento de outras mais e, por isso, a autora defende a necessidade de se redesenhar o espaço do problema de pesquisa ao invés de procurar algo dentro de um espaço de estudo já dado. Desta forma, a autora explica que é preciso se chegar aos motivos pelos quais as perguntas são elaboradas a fim de fomentar o tema e o campo do empreendedorismo.

$\mathrm{Na}$ busca de um entendimento ampliado do empreendedorismo, Brush, Manolova e Edelman (2008, p. 547) apontaram que "o processo de criação de novo empreendimento é fundamental para o campo do empreendedorismo. [...] a atividade central do empreendedorismo é a criação de novas organizações". Por outro lado, Borba, Hoeltgebaum e Silveira (2011), a partir de análise das publicações do Academy of Management Meeting, concluíram que houve uma mudança na produção científica em empreendedorismo, com foco mais acentuado na ação do empreendedor ao empreender.

A partir dessas considerações iniciais e procurando avançar ainda mais nos estudos e pesquisas sobre empreendedorismo, o presente artigo pretende verificar como se dá a criação de uma nova organização, descrevendo as ações realizadas pelos empreendedores. Para tanto, utilizou-se das propriedades das organizações emergentes descritas por Katz e Gartner (1988) como dimensões principais de análise. São elas: Intencionalidade, Recursos, Limites e Trocas.

Por fim, é importante dizer que o presente estudo está estruturado em quatro seções adicionais. Primeiramente é apresentado o referencial teórico-empírico que sustenta a pesquisa realizada. Em seguida, são descritos os procedimentos de pesquisa adotados no estudo. A quarta seção faz a descrição e análise dos resultados para, por fim, chegar-se às considerações finais. 


\section{Empreendedorismo e propriedades das organizações emergentes}

O empreendedorismo possui significados diversos dentro de um campo extenso de atuação. Este termo pode assumir uma miríade de conotações, desde as de tipologia científica até as de senso comum (COLBARI, 2007).

A origem do termo empreendedorismo vem da palavra francesa entrepreneur que, segundo o dicionário escolar Francês/PortuguêsPortuguês/Francês, significa "empreendedor; empreiteiro; empresário". Na mesma referência são mencionados os verbos entreprendre, o qual assume as denotações de "empreender; tomar de empreitada [...]", e enterprise como "empresa; empreendimento, empreitada; estabelecimento" (CORRÊA, 1958, p. 219).

Seu uso, segundo Martinelli (1994), começou no século XVI no contexto do capitão que tinha por objetivo contratar soldados para o monarca. Passou para o século XVIII significando àquelas pessoas que corriam risco pelo investimento de seu capital em estabelecimento comercial, especialmente na indústria, ou que inovavam na área agrícola.

Contudo, Filion (1999) reitera a afirmação de estudos anteriores que defendem que no contexto do empreendedorismo, e mais especificamente da função empreendedora, foi o economista Richard Cantillon quem primeiro teve uma concepção mais geral da palavra, seguido pelo também economista Jean-Baptiste Say.

Todavia, é importante ressaltar a dificuldade em saber qual dos dois foi 0 primeiro estudioso da área. Filion (1999, p. 07) defende que "como Say foi o primeiro a lançar os alicerces desse campo de estudo, pode-se considerá-lo como o pai do empreendedorismo". Já Praag (1999) diz que Cantillon foi o cientista mais antigo que atribuiu considerável atenção ao empreendedor, introduzindo seu conceito e reconhecendo a existência da função empreendedora no sistema econômico. Mas o mais importante de se mencionar é que para ambos os precursores, Cantillon e Say, empreender era assumir riscos (FILION, 1999).

De acordo com Praag (1999), Cantillon descreve o empreendedor como arbitrário, convivendo com risco e incerteza. Já o descrito por Say era líder, coordenador e gerente, sendo enfatizando dentro de uma questão mais gerencial, 
apresentando características como julgamento, perseverança e conhecimento do mundo e de seu próprio negócio (PRAAG, 1999, p. 315).

Conforme evidenciam Bruyat e Pierre-André (2000), Say defendia que o empreendedorismo ocorre quando alguém (o empreendedor) obtém e organiza os fatores de produção para a geração de valor.

Entretanto, não se pode esquecer que o economista Schumpeter é o principal teórico clássico da área, associando o empreendedorismo à inovação. Segundo ele, o empreendedor é um inovador e a inovação traria desenvolvimento econômico por meio de uma combinação diferenciada de recursos já existentes (LEITE; MELO, 2008).

Não é mera coincidência que os três autores citados acima (Cantillon, Say e Schumpeter) sejam economistas. Afinal, é no campo da Economia que começaram os estudos e focos sobre o empreendedorismo (GUIMARÃES, 2002).

É bem verdade que o empreendedorismo apresenta uma multiplicidade de conceitos, origens e definições. Como bem pontua Ferreira (2012, p. 22): "a apropriação de estudos de outras áreas resulta em grupos que definem 0 empreendedorismo ora como elemento da economia, ora como característica individual e também fenômeno social". Assim, há as abordagens do empreendedorismo baseadas na Economia, Psicologia e Sociologia. Rocha (2010), entretanto, cita outra mais: a perspectiva do empreendedorismo sob uma visão administrativa.

A perspectiva econômica do empreendedorismo tem no economista Joseph Schumpeter o principal nome e enfatiza a relação deste tema com a questão da inovação e sua importância para o desenvolvimento econômico (LEITE; MELO, 2008, FILION, 1999). Aqui, ressalta-se que o empreendedorismo está ligado com a noção de "destruição criativa", isto é, na introdução de inovações ou de novas combinações de algo que já existe.

Schumpeter expunha esta destruição criativa, ou seja, o fato de que inovações e mudanças na forma de produção é que caracterizavam o empreendedorismo. Para ele, ao empreendedor cabia a responsabilidade de realizar novas combinações que alterava algo já existente para surgir outro melhor em prol do desenvolvimento econômico. "Inovar, na visão Schumpeteriana, significa 
introduzir, por meio de um agente dotado de uma alta capacidade criadora, algo que rompe com o sistema econômico como um todo, produzindo ou induzindo uma mudança radical" (GOMES; LIMA; CAPELLO, 2012).

As inovações para Schumpeter ocorriam de cinco maneiras, todas descritas por Moricochi e Gonçalves (1994): a) pela introdução de um novo bem ou de nova qualidade de um bem já existente; b) pela introdução de um novo método de produção de um bem; c) pela descoberta de nova fonte de matéria-prima; d) pela abertura de novo mercado; e e) pela reorganização de um mercado, como criação ou ruptura de um monopólio.

Como se depreende, o empreendedorismo de Schumpeter advinha de um ator líder e inovador que, por isso, se caracteriza como uma condição temporária de uma pessoa que seria denominada de empreendedora apenas enquanto permanecesse inovando em seu mercado (PRAAG, 1999).

Ainda dentro desta visão do empreendedorismo na economia, Baumol (1993) dividiu os empreendedores em duas classes: os inovadores e os que organizam negócios. Nas definições de empreendedorismo desta abordagem, conceitos como assumir riscos, inovação e desenvolvimento econômicos se fazem constantes. Também pode-se perceber, conforme Gomes, Lima e Capello (2012), que entre os economistas, o empreendedorismo é ligado à ideia de inovação e os empreendedores seriam os agentes que as trariam ao mercado, alavancando o desenvolvimento. Em outras palavras, os empreendedores seriam líderes proativos e inovadores que executam previsões.

Dentro da visão econômica, Ferreira (2012) expõe que o fator comum dentre todos os estudiosos do tema é a relação do empreendedorismo com o crescimento da economia. As críticas que se debruçam sobre esta abordagem expõem que a questão da inovação, por exemplo, poderia ser consequência de esforços da organização em aplicar seus recursos acumulados e não, necessariamente, resultado de uma ação empreendedora (MORICOCHI; GONÇALVES, 1994). Também, como exposto por Filion (1999), esta perspectiva não olha para o comportamento dos empreendedores. Sendo assim, uma nova abordagem emerge: a de origem na Psicologia, também chamada de comportamentalista. 
Sob este prisma, Filion (1999) registra que o psicólogo David McClelland foi o responsável pelo crescimento deste foco mais comportamental. Assim, o significado de empreendedorismo repousa não em sua contribuição econômica, mas antes, nos atributos psicológicos presentes em si (LEITE; MELO, 2008). Desta forma, os estudos devem definir o que são os empreendedores e quais características possuem (FILION, 1999). Como se observa, o conceito de quem empreende muda.

Por meio de sua busca em procurar entender a razão pela qual algumas pessoas se tornam empreendedoras e outras não, McClelland se voltou para um lado mais psicológico, ligado à realização. Para ele, inclusive, essa força de realização estaria ligada ao próprio desenvolvimento econômico. Quanto mais força para realizar, mais desenvolvimento haveria. Esta visão com bases na Psicologia, aliás, segundo Gomes, Lima e Capelle (2012), volta-se para características do empreendedor, abrangendo sua subjetividade, comportamento e atitudes.

Nesta abordagem Psicológica, Filion (1999) explica que McClelland dividiu a população em dois grupos: quem empreenderia, como sendo aqueles que aceitam desafios e riscos, e aqueles que não estariam dispostos a correr esses riscos. $O$ primeiro grupo, da minoria, eram os possíveis empreendedores. Com isso, McClelland traçou perfis de empreendedor (FILION, 1999). Algumas das características associadas ao empreendedor seriam: autoconfiança, determinação, criatividade, otimismo, visão de futuro, abertura a incertezas, coragem e liderança (FERREIRA, 2012).

Nas definições de empreendedorismo deste enfoque comportamental, podese inferir que questões como características das pessoas, além de capacidade de visão, estão presentes para diferenciar quem é empreendedor de quem não é. As críticas que aqui recaíram se embasavam no argumento de que McClelland não levou em consideração que as pessoas mudam de acordo com vários fatores, tais como: tempo, época de vida, contexto e desafios a enfrentar (GOMES; LIMA; CAPELLE, 2012).

Um novo enfoque emerge nos anos de 1980: o da Sociologia. Colbari (2007) considera que o empreendedorismo se tornou um movimento social devido às mudanças no mundo do trabalho. A autora, inclusive, afirma que 0 
empreendedorismo tanto pode apresentar-se como um fator que impulsiona o desenvolvimento econômico quanto como "uma estratégia meramente defensiva diante da crise do assalariamento" (COLBARI, 2007, p. 84). Dentro da visão sociológica, empreender aparece como sinônimo de iniciar negócios (FERREIRA, 2012).

Por fim, cabe destacar o empreendedorismo sob uma visão administrativa realizada por Peter Drucker. Drucker (1986) advoga que empreendedorismo é uma disciplina e que as figuras de empresário e empreendedor não devem ser confundidas porque, na verdade, são distintas. Para ele, "os empreendedores inovam" (DRUCKER, 1986, p. 39), "tentam criar valor e fazer uma contribuição" (DRUCKER, 1986, p. 45). Contudo, esta contribuição está intrinsecamente ligada à inovação que pode advir, segundo ele, de sete fontes de oportunidades inovadoras, das quais quatro são oriundas do ambiente interno da organização e três do ambiente externo.

Estas fontes são: o inesperado (sucesso, fracasso e evento externo inesperado), incongruência (entre a realidade como é e como deve ser), necessidade do processo (como fonte de inovação), estruturas da indústria e do mercado (de onde a empresa se situa), mudanças demográficas, mudanças em percepção (disposição, significado e ânimo) e conhecimento novo.

Diante destes diferentes olhares, é importante entender que

[...] de modo geral, a literatura acadêmica estuda o empreendedorismo como um tipo de ação econômica e o empreendedor como um ator social a quem corresponde um tipo de prática ligada à liderança e à inovação, criação e crescimento de empresas. (LEITE; MELO, 2008, p. 39-40).

Neste sentido, Gartner (2001) escreveu um artigo no qual, por meio de uma metáfora, coloca que o empreendedorismo é visto sob diferentes perspectivas, tendo, consequentemente, uma miríade de definições e características atreladas a si, dependendo do foco utilizado, possuindo problemas de integração destes diferentes pontos de vista. No entanto, ainda, conclui que os estudos em torno do empreendedorismo não levam a uma teoria abrangente do campo, porque não há teoria de empreendedorismo que possa dar conta da diversidade e complexidade deste fenômeno. 
Pode-se dizer, então, que o empreendedorismo enquanto fenômeno é muito maior do que uma concepção puramente econômica ou uma abordagem estritamente comportamentalista. Seu campo é vasto e afeta como também é afetado por diversas áreas do conhecimento. Por tal razão, Ferreira propõe que se considere o empreendedorismo sob um prisma de "fenômeno social, um comportamento, ação e situação, que é observado na sociedade ocidental moderna. O empreendedorismo é efetivado pelo indivíduo e afetado pela situação concreta em que ele se encontra" (FERREIRA, 2012, p. 30).

Corroborando o assunto, o fenômeno do empreendedorismo apresenta diversos significados, se fazendo presente não apenas na inovação ou abertura de organizações, mas também e de igual forma, em contextos como: no trabalho assalariado, nos governos, nas hierarquias das empresas e na comunidade (COLBARI, 2007, p. 76). Além disso, Hisrich, Peters e Sheperd defendem que empreender é gerar mais riqueza, definindo o empreendedorismo como sendo:

[...] o processo de criar algo novo com valor, dedicando o tempo e o esforço necessários, assumindo os riscos financeiros, psíquicos e sociais correspondentes e recebendo as consequentes recompensas da satisfação e da independência financeira e pessoal. (HISRICH; PETERS; SHEPERD, 2009, p. 30).

Os autores argumentam que o processo de empreender abrange as fases de encontrar, avaliar e desenvolver oportunidades rumo à criação de um empreendimento. Esse processo de empreender é a busca de uma nova organização para agregar novos produtos e serviços em mercados atuais, produtos e serviços atuais em novos mercados ou para criar uma nova empresa (HISRICH; PETERS; SHEPERD, 2009). Neste processo, as pessoas agem e tomam decisões quanto a seguir ou não a oportunidade e criar ou não sua própria organização.

Para Bygrave (2007), o processo empreendedor abrange atividades e ações relacionadas à criação de organizações. Bygrave (2007, p. 02), ao defender que o "empreendedor é alguém que percebe uma oportunidade e cria uma organização para persegui-la", define o processo de criação de uma organização. Ou seja, o processo empreendedor como as atividades, ações e funções com o fim de criar organizações para explorar as oportunidades de mercado. Mas quando um novo 
negócio é aberto, muito antes, alguém, o empreendedor, já vinha se debruçando sobre um sonho, uma ideia, um projeto de vida: o de ter sua própria empresa.

No entanto, em 1988, Katz e Gartner chamaram a atenção para a necessidade de que os estudos sobre a criação de empresas procurassem efetivamente estudar esse fenômeno. Para esses autores, a maioria dos estudos sobre empreendedorismo tinha como objeto, organizações já existentes, o que não era, segundo eles, uma forma adequada de estudar sobre empreendedorismo. Assim, defenderam que era necessário investigar não apenas o período pósabertura da empresa recém-criada, mas, também sua concepção, pré-abertura e momentos iniciais. Ambos os autores colocaram como desafio e uma necessidade a exploração do território entre o antes e o depois de se empreender.

Para esse fim, foi proposto e descrito quatro propriedades que, segundo os autores, podem ser identificadas no que denominaram organizações emergentes e que advêm das interações entre os agentes e o meio ambiente: Intencionalidade, Recursos, Limite e Troca (Intentionality, Resources, Boundary and Exchange). Essas propriedades são necessárias para tornar a organização emergente em uma organização real, abrangendo, então, o espaço entre uma pré-organização e uma nova organização (KATZ; GARTNER, 1988).

A propriedade da Intencionalidade (Intentionality), de característica processual, envolve: a) as metas desenhadas pelo empreendedor e pelos diversos setores do ambiente no qual se insere o empreendimento; e b) o processo de busca de informações para se alcançar o que se almeja (KATZ; GARTNER, 1988). A intenção é uma orientação estratégica do empreendedor ao criar um negócio (KUNDU; KATZ, 2003).

A intenção engloba o buscar fazer sentido, organizar e construir uma realidade, onde alguém busca informações para o alcance de metas, como o de criar a organização. A Intencionalidade da organização recém-criada tende a seguir e a ser confundida com as intenções (metas) do ambiente em que a organização se insere, passando a tornar-se cada vez mais singular à própria organização à medida que esta se torna distinta e detentora de personalidade própria (KATZ; GARTNER, 1988).

DOI: 10.14211regepe32128. FERREIRA, F. L. A.; GIMENEZ, F. A. P.; AUGUSTO, P. O. M. Empreendedorismo e o processo de criação de uma nova organização. Revista de 
A propriedade Recursos (Resources), de característica estrutural, concerne aos componentes físicos (recursos financeiros, materiais, imóveis e humanos) a serem aplicados no negócio da empresa, se opondo aos componentes informacionais que se localizam na intencionalidade (KATZ; GARTNER, 1988). Eles englobam, também, tempo e experiência que o empreendedor traz consigo para iniciar um novo negócio (BRUSH; MANOLOVA; EDELMAN, 2008).

A propriedade Limite (Boundary) é definida como a barreira entre a organização e seu ambiente. A identidade da organização toma forma perante o ambiente com o qual tem este limite (KATZ; GARTNER, 1988). Refere-se à lacuna na qual a empresa possui controle sobre recursos no ambiente que a abrange (BRUSH; MANOLOVA; EDELMAN, 2008). É pelo estabelecimento dos limites que a identidade de uma organização é firmada, sendo que esta propriedade tem a característica de isolar a Intencionalidade efetivada e os recursos conseguidos para iniciar a organização (KATZ; GARTNER, 1988).

A propriedade Troca (Exchange) é definida pelas transações realizadas dentro da própria empresa, bem como entre a empresa e suas fronteiras. Seu fim só se dá com o término da própria organização (KATZ; GARTNER, 1988). Ela reflete a Intencionalidade e os Recursos atravessando os limites da organização (KUNDU; KATZ, 2003). As trocas com os diversos ambientes (legal, governamental, e outros) beneficiam a empresa e ocorrem quando as outras três propriedades estão já situadas na organização (KATZ; GARTNER, 1988).

Realizando um teste empírico com dados longitudinais do ano de 1998 com empreendedores que iniciavam suas empresas, Brush, Manolova e Edelman (2008) buscaram compreender os efeitos destas quatro propriedades das organizações emergentes na probabilidade de continuação das organizações. No estudo, consideraram como variáveis da Intencionalidade: o plano de negócio, a identificação da oportunidade, eventos, cursos e início do trabalho. Como Recursos: equipe, materiais, equipamentos e investimentos. Limite foi compreendido por tudo que fosse dar nome à empresa, como: endereço, e-mail, site, símbolo que a represente. Já a Troca como as transações realizadas a rigor.

Como conclusão do teste, os autores perceberam que todas as propriedades (Intencionalidade, Recursos, Limites e Trocas) estão associadas positivamente com 
a probabilidade de continuar os esforços em construção de uma nova organização, diminuindo o risco de dissolução do novo negócio, sendo, portanto, "necessárias para a sobrevivência da organização" (BRUSH; MANOLOVA; EDELMAN, 2008, p. 563). Em outras palavras, a existência das propriedades se reveste de fundamental importância como insumo, matéria-prima a ser obtida para a nova empresa que se forma.

Há mais de duas décadas, Katz e Gartner (1988) haviam entendido que apesar de as propriedades poderem caracterizar uma organização plena, completa, é necessário focar no processo de evolução das organizações, pois as pesquisas têm como escopo os empreendimentos quando já criados e em andamento. As análises e estudos precisam responder "Como as organizações vem a existir?" (KATZ; GARTNER, 1988, p. 437).

Atualmente, estudiosos como Morris et al. (2011) postularam que as ações que levam uma organização a existir devem ser observadas no dia a dia de seu empreendedor. Mesmo com o espaço de tempo de mais de 20 anos, ambas as preocupações estão relacionadas, deixando uma lacuna a ser preenchida pelas pesquisas nas ciências, o que este artigo busca, paulatinamente, preencher.

Neste momento, após a apresentação do contexto teórico no qual este estudo se baseou, é importante evidenciar os procedimentos metodológicos adotados para descrever a criação de quatro empreendimentos à luz da proposição de Katz e Gartner (1988).

\section{Delineamento metodológico}

Os métodos científicos integram as ciências, sendo o trajeto, o caminho a se trilhar para atingir os objetivos estabelecidos (MARCONI; LAKATOS, 2010).

A presente pesquisa buscou responder como se dá a criação de uma nova organização, identificando as ações dos empreendedores no processo de empreender, descrevendo as propriedades das organizações emergentes de Katz e Gartner (1988). Para isso, foram acompanhados quatro empreendedores da cidade da Curitiba-PR, cujos negócios estivessem em fase de criação ou em estágio inicial (máximo de três anos e meio de atividade). 
A abordagem utilizada foi a qualitativa, pois:

[...] parte de questões ou focos de interesses amplos, que vão se definindo à medida que o estudo se desenvolve. Envolve a obtenção de dados descritivos sobre pessoas, lugares e processos interativos pelo contato direto do pesquisador com a situação estudada, procurando compreender os fenômenos segundo a perspectiva dos sujeitos, ou seja, dos participantes da situação em estudo. (GODOY, 1995, p. 58).

Bardin (1977 apud GOMES; LIMA; CAPELLE, 2012, p. 21) também expõe que em uma abordagem qualitativa é levado em consideração "a presença ou ausência de uma dada característica de conteúdo ou de um conjunto de características [...]" em oposição à busca da frequência de certas circunstâncias informação da abordagem quantitativa. Sendo assim, buscou-se verificar as ações executadas por empreendedores para a abertura de seu próprio negócio sem a utilização de instrumental estatístico para o tratamento dos dados advindos da pesquisa.

O corte do tempo tem característica longitudinal, pois autores como Aldrich e Martinez (2001) defendem a necessidade de mais estudos longitudinais ao se pesquisar sobre empreendedorismo. Nesse sentido, e através de uma pesquisa de campo, foram realizadas entrevistas mensais com os informantes num período médio de junho de 2012 a fevereiro de 2013, dependendo da incursão de cada respondente no estudo.

Os dados da pesquisa são do tipo primário, oriundos de procedimentos de coleta de dados, consubstanciados pela técnica de entrevista guiada. De acordo com Richardson (2007), a entrevista guiada é utilizada para pesquisar uma experiência específica na qual o entrevistado está envolvido. Por meio dela, é possível conseguir um aprofundamento da situação com os posicionamentos do informante.

$\mathrm{Na}$ entrevista guiada, o entrevistador concebe os pontos a serem tratados, os quais são respondidos de forma livre, porém guiada pelo pesquisador. Simpson (2009 apud GOMES; LIMA; CAPELLE, 2012) defende que entrevistas são produtivas para se analisar a prática de fenômenos, porque, por meio delas é possível o acesso às formas de fazer sentido que as pessoas utilizam. 
Finalmente, estes dados coletados foram analisados pela ótica da técnica de análise de narrativa. Labov e Waletsky (1967), em estudo que trata a análise de narrativa como versão oral de experiência pessoal, conceituam-na como uma recapitulação de experiências passadas, respeitando a ordem de ocorrências dos acontecimentos como de fato se apresentaram.

Para Barthes et al. (1973, p. 114) a narrativa é um discurso que integra acontecimentos sucessivos de interesse sobre uma ação humana, pois "é somente por relação com um projeto humano que os acontecimentos tomam significação e se organizam em uma série temporal estruturada".

\section{Apresentação e análise dos dados}

Esta seção apresenta uma síntese de cada organização criada. Em seguida, com base na análise das narrativas, detalha-se o processo de criação de todas elas, em conjunto.

Eventos de churrasco

Esta empresa tem como negócio eventos de churrasco para as classes " $A$ " $e$ "B". A empresa vai até o local escolhido pelo cliente para o acontecimento do evento, levando insumos, materiais e recursos humanos para a sua devida realização. A empresa funciona através da sociedade de duas pessoas. Um dos sócios deixou, paulatinamente, seu emprego formal para se dedicar integralmente à organização, pois queria "ser dono do próprio nariz, rotina e horários". O outro empreendedor é dono de um açougue que está sob a gestão de sua família há décadas e é fornecedor das carnes para a empresa de eventos de churrasco.

Dentre as principais ações dos empreendedores da organização de eventos de churrasco, podem ser elencadas: a formalização e não atualização do plano de negócios; busca pelo SEBRAE com posterior desistência por não considerar que foi de grande valia; análise de mercado, concorrência, clientes, pesquisa de mercado; inserção em meios virtuais (facebook, fan page); participação em eventos da área do negócio; parcerias, definição de posicionamento para classes "A" e "B", 
padronização de cardápios com base na concorrência; controle do capital de giro, entradas e saídas, controle de custos e precificação; aquisição de materiais de trabalho com recursos dos próprios sócios; contratação de pessoal free lancers; locação de espaço próprio e contratação de profissional administrativo no decorrer do aumento da clientela.

Consultoria em recursos humanos

Esta organização consiste em uma consultoria em Recursos Humanos. Tudo começou quando sua empreendedora, enquanto servidora pública, deixou o posto de um cargo de confiança na área de Recursos Humanos onde exercia suas atividades com dedicação integral e retornou a sua atuação em tempo parcial. Com isso, decidiu que queria outro desafio profissional, além do seu como servidora.

No entanto, pretendia para si algo que não fosse como um segundo emprego formal, antes o contrário: uma oportunidade que lhe fosse mais flexível, de modo a poder conciliar com o seu vínculo empregatício atual. Então, tendo dedicado os últimos anos de sua vida a estudar, aplicar e difundir a área de Recursos Humanos, ela pretendia que este outro desafio permeasse uma área de trabalho cujo escopo fosse este, o de RH.

Dentre as principais ações da empreendedora da consultoria em Recursos Humanos, tem-se: contratação de coaching; participação na Sociedade Brasileira de Dinâmica de Grupos; curso de formação de consultores e grupos de discussão da área de $\mathrm{RH}$; formalização e não atualização do plano de negócios; análise da concorrência e pesquisa de mercado; cartão de apresentação; associação em cooperativa para utilização de espaço e know-how; estabelecimento de público-alvo quanto a não ser "top" e sim uma consultoria que atenderia todo tipo de empresa; elaboração de propostas de produto, definições de precificação e contratação com base na concorrência; controle financeiro das entradas e saídas; oferta de palestras gratuitas a pessoas chave para mostra de expertise; contratação de profissional para divulgação e parcerias diversas. 
Escola de artes

Esta escola de artes tem sede num atelier e oferta cursos para um públicoalvo a partir de três anos de idade. A ideia do negócio nasceu da vivência de uma de suas idealizadoras quando cursava o último ano de Graduação em Pintura. Na ocasião, dividiu a intenção com uma amiga e juntas almejavam criar uma escola de Pintura com ênfase em terapia: "faça um trabalho que represente a alegria, a tristeza ou o medo".

Juntamente disto, também havia a sua maior motivação para se tornar empreendedora, abrindo a escola de artes, que veio com o vislumbre da possibilidade de se dedicar à sua filha, possibilidade que, para ela, só seria proporcionada ao ser dona do próprio negócio.

Dentre as principais ações da empreendedora da escola de artes, apresentam-se: procura pelo SEBRAE e desistência por não ter considerado de grande valia; procura por ONG fomentadora de empreendedorismo; apadrinhamento nesta ONG; formalização e não atualização do plano de negócios; inserção em meios virtuais (facebook e site); pesquisa de mercado, clientes e concorrentes bem como a pesquisa de dados secundários; declaração de missão; confecção de folders; contratação de professores; desenvolvimento e remodelagem constante das aulas; desenho da identidade visual; locação de imóvel; definições de precificação e contratação com base na concorrência; realização de oficinas de artes para mostra de trabalho; controle financeiro de entradas e saídas.

Sanduíches naturais para eventos de coffee breaks

A criação desta organização começou com a fabricação e comercialização de sanduíches naturais, passando para a entrega delivery de combos naturais compostos por sanduíche natural, suco e barra de cereais. Em paralelo, oferece consultoria de aconselhamento nutricional (sua empreendedora é Nutricionista de formação) para chegar na preparação de coffee breaks e cupcakes. Simultaneamente, estabeleceu uma cantina em uma ONG na qual comercializa seus 
produtos, onde possui parceria com uma cozinheira que lhe ajuda no fornecimento de salgados e que mais tarde seria uma de suas parceiras nos coffees.

Dentre as principais ações da empreendedora da empresa que começou com o negócio de fabricação e comercialização de sanduíches naturais chegando à preparação de coffee breaks, são consideradas: procura pelo SEBRAE e ONG fomentadora de empreendedorismo; apadrinhamento na ONG; formalização do plano de negócios (pautado no sanduíche natural) e não atualizado para os coffee breaks; declaração de missão; estudo do mercado, concorrência e clientes; divulgação, confecção de folders; desenvolvimento de site e facebook; remodelagem constante do produto devido às pesquisas de mercado e estudo de custo/benefício; desenho de identidade visual; parcerias; controle financeiro de estoques e custos; empréstimo microcrédito.

Ações realizadas nos quatro processos de criação de nova organização pesquisados

Comparando os quatro casos de criação de empresas explanados na pesquisa, podem ser elencadas as situações cernes que integraram os referidos processos em todos ou na maioria deles (Quadro 1). 


\begin{tabular}{|c|c|}
\hline & ACÕES \\
\hline INTENCIONALIDADE & $\begin{array}{l}\text { - intenção de abrir o negócio; } \\
\text { - aprimoramento na área do negócio; } \\
\text { - análise da concorrência e definição do público-alvo; } \\
\text { - plano de negócios (que depois ficou desatualizado); } \\
\text { - busca por orientação para abertura da empresa; } \\
\text { - declaração de missão; } \\
\text { - planejamento dos meios de divulgação; } \\
\text { - pesquisa de mercado. }\end{array}$ \\
\hline RECURSOS & $\begin{array}{l}\text { - do conhecimento e ou da experiência no ramo de negócio; } \\
\text { - bens de uso pessoal que se tornam da empresa; } \\
\text { - retroalimentação da clientela para alterar escopo do negócio; } \\
\text { - copiar da concorrência os aspectos que estão dando certo e aplicar em } \\
\text { seu negócio, dando a cara de sua empresa. }\end{array}$ \\
\hline LIMITES & $\begin{array}{l}\text { - tentativa de busca pelo diferencial competitivo; } \\
\text { - nome da empresa; } \\
\text { - identidade visual; } \\
\text { - cartão de apresentação; } \\
\text { - inserção em meios virtuais; } \\
\text { - adaptação de sua empresa aos aspectos da concorrência observados e } \\
\text { tidos como sucesso. }\end{array}$ \\
\hline TROCAS & $\begin{array}{l}\text { - promoção de produtos/serviços para divulgação; } \\
\text { - aprendizagem no ramo e alteração do produto/serviço prestado; } \\
\text { - estabelecimento de redes de contato; } \\
\text { - gestão prioritária em áreas de Finanças e Marketing e focada em seus } \\
\text { aspectos elementares, tais como controle de estoque, entrada e saída e } \\
\text { divulgação da empresa. }\end{array}$ \\
\hline
\end{tabular}

QUADRO 1 - Integração dos Processos de Empreendedorismo Estudados

Fonte: Os autores ( 2013).

Pode-se dizer, tendo por base o que foi observado, que a criação de uma organização começa pelo intento de alguém em levar a cabo tal intenção, enfrentando os obstáculos. Esses obstáculos podem ser tanto de ordem pessoal, no sentido de assumir a escolha em empreender, tido como algo incerto, arriscado e inseguro, mas que traz uma realização pessoal que supera os reveses, quanto de ordem profissional, inerentes ao empreendedorismo e gestão.

Este início é marcado por uma preparação técnica em relação ao produto e serviço que se pretende oferecer, busca por apoio em sociedade, parcerias, instituições da área de empreendedorismo e afins. É importante também realizar um estudo do mercado, mesmo que de modo rudimentar, básico. O plano de negócios é escrito por ser considerado importante. Os recursos são de ordem pessoal do empreendedor, adquirindo apenas 0 essencialmente necessário para o funcionamento do negócio, emprestando o mínimo possível de recurso financeiro, seja pelo medo do risco ou pela dificuldade encontrada quando se procura uma instituição bancária. 
O negócio começa, sem necessariamente a empresa estar formalmente instituída. A pesquisa de mercado, clientes, concorrentes, tentativa de busca por diferencial competitivo, estabelecimento de redes, estar presente em cursos e eventos da área são prioridades na vida do empreendedor. À medida que a empresa funciona, a premência de conceber e executar atividades de gestão emerge, como o financeiro. Este, no entanto, é simplista ao ponto de servir ao empreendedor como ferramenta que lhe mostre o quanto de receita precisa entrar, o que realmente está entrando e o que está sendo gasto.

O empreendedor, ao legalizar a empresa, insere-se em meios virtuais e redesenha o produto e serviço oferecido. Isto porque o produto anteriormente oferecido não atende ao público-alvo ou há outra forma que traga menores custos (quando há este cálculo) ou mais receita. Também aparece a preocupação com a imagem da empresa em termos de identidade visual, apresentação e declaração de missão. Assim, os papéis de empreendedor e de gestor se confundem, se misturam e tendem a se tornar único, centrados na figura do praticante principal da criação da organização, alguém que mostra um estado de otimismo no seu negócio e na crença de que dias melhores virão, dependendo de fatores diversos, mas, principalmente, dele mesmo, por meio de suas ações em seu negócio recém-criado.

\section{Considerações finais e recomendações}

Antes de tudo, vale lembrar que estudiosos citados por Ferreira (2012) esclareceram que o empreendedorismo vivia sua infância no final do século passado. Contudo, vive atualmente o período de sua adolescência e, por isso, "pode-se entender que, de forma geral, ainda há espaço para avanços teóricos" (FERREIRA, 2012, p. 15).

Neste sentido, a presente pesquisa buscou responder a indagação de como se dá a criação de uma nova organização, identificando as propriedades de organizações emergentes descritas por Katz e Gartner (1988), quais sejam: Intencionalidade, Recursos, Limite e Troca, por meio das ações dos empreendedores. Para isso, foram acompanhados longitudinalmente quatro empreendedores de Curitiba-PR por meio de entrevistas guiadas e analisadas pela 
técnica de análise de narrativa, a fim de verificar como se deu a criação das organizações.

Os resultados encontrados mostraram que na formação e continuação da empresa, as quatro propriedades das organizações emergentes se fizeram presentes por meio de diversas ações dos empreendedores. Para criar a organização, os empreendedores buscaram, além do apoio de outra pessoa, orientação em alguma organização, na própria formação profissional ou em assessoramento de coaching para sua Intencionalidade em criar o negócio.

Todos fizeram plano de negócios, apesar de considerarem-no atualmente ultrapassado devido ao que desenvolveram de seus produtos e serviços, e sua atualização não foi escrita por considerarem que havia outras prioridades. Apenas metade deles fez a declaração de missão e todos foram se aprofundar dentro do escopo de seu negócio, seja por cursos, palestras ou atividades afins.

Procurar parcerias já antes de criar a organização, mais do que uma prática institucionalizada num mercado global e permanentemente mutável, pode indicar o sentimento de receio do empreendedor quando decide realizar seu projeto de vida, bem como a humildade em admitir que não possui todos os conhecimentos e comportamentos imprescindíveis para assumir de fato o papel de empreendedor. De igual forma, pode sinalizar que o contexto brasileiro para empreender em seus diversos contextos (político, legal, social e econômico) ainda carece de melhores políticas sociais de incentivo ao empreendedorismo.

Para realizar suas intenções, os empreendedores utilizaram, na maioria dos casos, recursos próprios. Os que foram sendo adquiridos vieram por recursos financeiros próprios e ou dos pais. Apenas um dos empreendedores realizou empréstimo para aumento de recursos físicos. Estes recursos, definidores da capacidade instalada de cada empreendedor, foram buscados também por parcerias com o sócio ou com a adesão à cooperativa. Porém, o recurso unânime foi o da experiência do empreendedor.

Vale citar que em um caso, a experiência do empreendedor foi proveniente de formação acadêmica e experiência profissional, e em outro, da convivência com o sócio que é proprietário de outra empresa correlata à que foi criada, suprindo em capital intelectual àquela que estava se formando. 
Os limites destas empresas, ao utilizar a Intencionalidade e os Recursos para formar a identidade da organização e controlar seu espaço, se pautaram em ações como identidade visual, site, página no facebook, cartões de apresentação e até mesmo a tentativa de definição de algum diferencial.

As dimensões anteriores foram condições necessárias para que a organizações efetivamente realizassem as trocas. Estas ocorreram por meio de parcerias com fornecedores e outras empresas do ramo com alguma especialidade em produto/serviço afim ao da organização. Nestas transações, marcadas por uma visão prática das operações, foi essencial: a divulgação constante por internet, folders e, principalmente, o boca a boca; o estudo da concorrência por meio de contato; pesquisas de satisfação; simplificação da gestão financeira para questões de capital de giro, controle de contas e fluxo de caixa; gestão de pessoas simplificada aos sócios e alguns poucos profissionais contratados.

A partir dos resultados encontrados, algumas constatações podem ser feitas, tais como: empreender é um projeto dividido com outras figuras; empreender provoca no empreendedor o desafio de aprendizado constante; áreas de Finanças e de Marketing são prioridade, com o adendo de que delas só se pratica uma parte elementar; a centralização de gestão de pessoas apenas na figura do empreendedor, fazendo tudo e tendo que priorizar e até relegar atividades para dar conta; a preocupação em busca de um diferencial que, muitas vezes, não é efetivamente um diferencial, mas apenas uma característica de seu produto/serviço; plano de negócios é ferramenta considerada por eles como essencial, mas na prática é esquecida e não atualizada.

Por fim, recomenda-se que, para estudos futuros, algumas limitações desta pesquisa sejam superadas, tais como: que o acompanhamento de um processo de criação de uma organização ocorra num tempo maior de acompanhamento do empreendedor, bem como juntamente da aplicação de entrevistas; se faça uso do método da observação, de modo que o pesquisador possa acompanhar as ações dos empreendedores no processo de criação de sua organização. Isso poderá enriquecer ainda mais o campo do empreendedorismo para que, a partir de novas descobertas, novos horizontes surjam. 
Por derradeiro, cumpre lembrar o argumento de Aldrich e Martinez (2001, p.

26): "Paradoxalmente, quanto mais aprendemos enquanto pesquisadores, mais descobrimos que precisamos saber ainda mais".

\section{Referências:}

ALDRICH, H. E.; MARTINEZ, M. A. Many are called, but few are chosen: an evolutionary perspective for the study of entrepreneurship. Entrepreneurship: theory \& practice, v. 25, n. 4, p. 41-56, 2001.

BARTHES, R. et al. Análise Estrutural da Narrativa. 3. Ed. Petrópolis: Vozes, 1973.

BAUMOL, W. Formal entrepreneurship theory in economics: existence and bounds. Journal of Business Venturing, v.8, n. 3, p. 197-210, maio 1993.

BORBA, M. L.; HOELTGEBAUM, M.; SILVEIRA, A.. A produção científica em empreendedorismo: analise do Academy of Management Meeting: 1954-2005. RAM - Revista de Administração Mackenzie, v. 12, n. 2, p. 169-206, mar./abr. 2011.

BRUSH, C. G.; MANOLOVA, T. S.; EDELMAN, L. F. Properties of emerging organizations: an empirical test. Journal of Business Venturing, v. 23, n. 5, p. 547566, set. 2008.

BRUYAT, C.; JULIEN, A-P. Defining the field of research in entrepreneurship. Journal of Business Venturing, v. 16, n. 2, p. 165-180, mar. 2001.

BYGRAVE, W. D. The entrepreneurial process. In.: BYGRAVE, W. D.; ZACHARAKIS, A. The Portable MBA in Entrepreneurship, 4. ed. New Jersey: John Wiley \& Sons, 2007.

COLBARI, A. L. A retórica do empreendedorismo e a formação para o trabalho na sociedade brasileira. In: Sinais - Revista Eletrônica - Ciências Sociais, Vitória, v. 1, n. 1, p. 75-111, abr. 2007.

CORREAA, R. A. Dicionário escolar Francês - Português / Português - Francês. 5. ed. Rio de Janeiro: FENAME - Ministério da Educação e Cultura, 1958.

COSTA, A. M.; BARROS, D. F.; CARVALHO, J. L. F. A dimensão histórica dos discursos acerca do empreendedor e do empreendedorismo. RAC - Revista de Administração Contemporânea, v. 15, n. 2, p. 179-197, mar/abr. 2011.

DRUCKER, P. F. Inovação e espírito empreendedor - prática e princípios. São Paulo: Cengage Learning, 1986. 
FERREIRA, J. M. A ação de empreender sob a perspectiva sócio-histórica de González Rey. 2012, 157 f. Tese (Doutorado em Administração) - Universidade Positivo, Curitiba, 2012.

FILION, L. J. Empreendedorismo: empreendedores e proprietários-gerentes de pequenos negócios. Revista de Administração de Empresas. São Paulo, v. 34, n. 2, p. 05-28, abr./jun. 1999.

GARTNER, W. B. Is there an elephant in entrepreneurship? Blind assumptions in theory development. Entrepreneurship Theory and Practice, v. 25, n. 4, p. 27-39, 2001.

GEM. Global Entrepreneurship Monitor. Empreendedorismo no Brasil. Relatório Executivo. Disponível em: < http://www.gemconsortium.org>. Acesso em 25 abr. 2014.

GODOY, A. S. Introdução à pesquisa qualitativa e suas possibilidades. Revista de Administração de Empresas, São Paulo, v. 35, n. 2, p. 57-63, mar./abr. 1995.

GOMES, A. F.; LIMA, J. B.; CAPELLE, M. C. A. Empreendedorismo e ações empreendedoras: perspectivas de análise. In: EGEPE, VII, 2012. Anais... Florianópolis: Encontro de estudos sobre empreendedorismo e gestão de pequenas empresas, 2012.

GUIMARÃES, L. O. A experiência universitária norte-americana na formação de empreendedores - contribuições das universidades de Saint Louis, Indiana e Babson College. 2002. 307 f. Tese (Doutorado em Administração) - Fundação Getúlio Vargas, São Paulo, 2002.

HISRICH, R. D.; PETERS, M. P.; SHEPERD, D. Empreendedorismo. Porto Alegre: Editora Bookman, 2009. 439 p.

KATZ, J.; GARTNER, W. B. Properties of emerging organizations. The Academy of Management Review, v. 13, n. 3, p. 429-441, jul.1988.

KUNDU, S. K.; KATZ, J. A. Born-international SMEs: BI-Level Impacts of Resources and Intentions. Small Business Economics, v. 20, n. 1, p. 25-47, fev. 2003.

KURATKO, D. F.; MORRIS, M. H.; SCHINDEHUTTE, M.; SPIVACK, A. J. Framing the entrepreneurial experience. Entrepreneurship theory and practice, Baylor, v. 36, n. 1, p. 11, jan. 2012.

LABOV, W.; WALETSKY, J. Narrative analysis: oral versions of personal experience. Journal of narrative \& Life History, v. 7, n. 1-4, p. 3-38, 1997.

LEITE, E. S.; MELO, N. M. Uma nova noção de empresário: a naturalização do "empreendedor". Revista de Sociologia e Política, Curitiba, v. 16, n. 31, p. 35-47, nov. 2008.

DOI: 10.14211regepe32128. FERREIRA, F. L. A.; GIMENEZ, F. A. P.; AUGUSTO, P. O. M. Empreendedorismo e o processo de criação de uma nova organização. Revista de Empreendedorismo e Gestão de Pequenas Empresas, v.3, n.2, p. 70-93, 2014. 
MARCONI, M. A.; LAKATOS, E. M. Fundamentos de metodologia de pesquisa. 7. ed. São Paulo: Atlas, 2010.

MARTINELLI, A. Entrepreneurship and Management. In: SMELSER, N; SWEDBERG, R. The handbook of economy sociology. EUA: Princeton, 1994.

MCCLELLAND, D. The achieving society. RJ: Expressão e Cultura, 1961.

MORICOCHI, L.; GONÇALVES, J. S. Teoria do desenvolvimento econômico de Schumpeter: uma revisão crítica. Informações Econômicas, São Paulo, v. 24, n.8, p. 27-35, ago. 1994.

RICHARDSON, R J. et al. Pesquisa social: métodos e técnicas. 3. ed.. São Paulo: Atlas, 2008, 336 p.

ROCHA, D. T. Política pública de estímulo ao empreendedorismo: o caso do programa universidade sem fronteiras - extensão tecnológica empresarial. 2010. 135 f. Dissertação (Mestrado em Administração) - Pontifícia Universidade Católica do Paraná, Curitiba, 2010.

SARASVATHY, S. D. The questions we ask and the questions we care about: reformulating some problems in entrepreneurship research. Journal of Business Venturing, v. 19, n. 5, p. 707-717, set. 2004.

SCHUMPETER, J. A teoria do desenvolvimento econômico. São Paulo: Abril, 1982.

SEBRAE. Serviço Brasileiro de Apoio às Micro e Pequenas Empresas. Disponível em: <http://www.ead.sebrae.com.br/hotsite/noticias/lernoticia.asp?noticia=5825>. Acesso em: 08 abr. 2012.

VAN PRAAG, C. M. Some classic views on entrepreneurship. De Economist, v. 147, n. 3, p. 311-335, set. 1999.

Artigo recebido em: 25/04/2014. Artigo aprovado em: 14/08/2014

DOI: 10.14211regepe32128. FERREIRA, F. L. A.; GIMENEZ, F. A. P.; AUGUSTO, P. O. M. Empreendedorismo e o processo de criação de uma nova organização. Revista de Empreendedorismo e Gestão de Pequenas Empresas, v.3, n.2, p. 70-93, 2014. 